\title{
Local NEEDS Implementation for All Programs
}

\author{
James G. Harris \\ Norm Rogers
Madeleine M. Johnson
Jay Waddell

Introduction:

SYNTHESIS is one of four existing NSF Engineering Education Coalitions (there are apparently plans to add two others this year to bring the total number to six). SYNTHESIS consists of eight universities: Cal Poly, Cornell, Hampton, lowa State, Southern, Stanford, Tuskgekee, and UC-Berkeley. It has been supported by NSF for over three years, being one of the first two-the other being ECSEL. The other two existing coalitions are GATEWAY and SUCCEED. One of the main goals of the SYNTHESIS coalition is the development of the National Engineering Education Delivery System (NEEDS). After giving a brief overview of the NEEDS, we give a description of our local implementation of the NEEDS concept, an implementation that can be used by all engineering programs to share curricular material in digital form.

\section{NEEDS Overview:}

NEEDS consists of three major components: a distributed database and network, a courseware studio, and a learning and delivery system. The NEEDS distributed database and network component supports the concept of a courseware curriculum matrix - an extensively crossed-indexed repository of interactive courseware modules, video segments. simulations, slide images, graphics, hardware links and text material (such as lecture notes, exercises or problem sets) - accessed by NEEDS servers which are connected to the National Research and Education Network (NREN), the information superhighway being proposed as the future goal of the Internet. Through the network, faculty and students in classrooms, courseware studios, laboratories. and their offices and rooms, will be able to access the curricular modules from terminals. microcomputers or workstations. Faculty will be able to find, preview, select, and program material for their classes quickly and easily. Students will be able to find and access tutorial material, as well as classroom and laboratory exercises. Although the NEEDS database is comprised of a distributed set of archive nodes, the NEEDS Access Server (NAS) provides a search engine over a centralized library catalog with pointers to the digital course material on the distributed nodes which serve it. Front-end interfaces to the NEEDS database such as the $\mathrm{NINa}$ (NEEDS Image Navigator) will extend the existing capabilities of current on-line library catalogs by supporting image searches for curricular modules and data elements stored in portable multimedia formats. The long term vision also includes access to the NEEDS database through some of the rapidly growing alternate modes of navigating the Internet, such as gopher and WAIS.

The NEEDS courseware development studio consists of a facility with hardware and software, network connectivity, a technical library, and support staff, that assists faculty in preparing curricular modules. The studio provides a cost-effective approach to the development of engineering courseware by integrating information in its multitude of forms and providing tools to facilitate the authoring process and minimizing the effort and resources required for the courseware development. Courseware development studios may include one central facility at the university level and/or college and departmental installations, as appropriate to each campus. Network connectivity will make possible a high degree of collaboration and resource-sharing between these various sites.

NEEDS delivery systems/learning environments consist of a range of high technology environments (including classrooms, computer and experimentation labs, design studios and small study groups) that have access to the NEEDS database, and are capable of presenting the courseware modules in real-time. It is 
important that there is faculty and student access to courseware modules through the local and NREN-supported network capability to either the university on-line library or the NEEDS database.

The Synthesis Coalition through its development of the NEEDS Infrastructure, and its pioneering use of this infrastructure to create new methods for teaching and learning undergraduate engineering principles through a collaborative process provides a model for the rest of the engineering education community. The long range goal is to develop the NEEDS Infrastructure into a national resource for the undergraduate engineering education community in the 21st century.

Local Cal Poly Implementation of NEEDS:

This is a brief description of the local NEEDS that has been developed

at Cal Poly. The implementation has all three components of the national NEEDS capability but at a local level that can be obtained and implemented in principle by all of the engineering programs. The distributed database and networking component consists of library references using the MARC catalog entry and the use of an anonymous ftp file account which contains at this time technology assisted instruction modules. The user uses the library on-line catalog service,

POLYCAT, to perform a search and locate the module, as they would for any library material. The MARC catalog entry has sufficient information to allow

the user to use the Internet ftp capability to retrieve the executable file. The MARC record was prepared by Madeleine Johnson, a library cataloger, and Jay Waddell, and follows accepted practices. A MARC catalog entry is listed below, followed by the instructions to create the ftp file for the module. The anonymous ftp file was prepared by one of our UNIX system administrators within the Department of Electronic and Electrical Engineering. The bjt module has been successfully located in the library and retrieved by students without any assistance.

To prepare the courseware modules, Cal Poly is using Authoreware Professional which is a campus standard; this authoring software is attractive because it currently is the only one that supports both the MAC and Windows platforms, and has an attractive price for educational institutions (about \$1K for one copy, and much less for multiple copies). We are using both of the platforms with the software. A typical Windows machine within the department is a 486-based computer with $8 \mathrm{MB}$ of RAM and $210 \mathrm{MB}$ of disk, with a $\mathrm{CD}$ player and sound system; the total cost was less than $\$ 3 K$. The university has a number of platforms with Authorware Professional, and a studio with peripherals for analog to digital conversion that can be accessed by both MACs and PCs; this central university resource is used to digitize slides and images, and to incorporate video data into modules. The cost of this equipment can vary, but a reasonable estimate these days for a fairly powerful set is around $\$ 70 \mathrm{~K}$, which consists of two platforms (MAC and PC) and peripherals.

The delivery system component on our campus presently consists of one distance learning classroom which is a university resource. That room cost approximately $\$ 120 \mathrm{~K}$, but portable systems can be obtained for as little as $\$ 20 \mathrm{~K}$. The capability consists of a CODEC which can achieve a motion rate of between 15 and 30 frames per second. This distance learning facility has been used during the past academia year to deliver classes to a classroom more than 200 miles away. The telecommunication costs for the classes are less than $\$ 40$ per hour. The classroom can be used to present digitized instructional materials to students at both local and remote locations. The university also provides laptop PC's on a check-out basis which can be used with large-screen video/data projectors in about a dozen specially equipped rooms. LCD overhead displays are likewise available for use in rooms not yet equipped with large-screen displays.

Students have access to the local campus network through modems and terminal rooms; this also gives them access to the on-line library catalog, POLYCAT. Many of the students are purchasing their own computers, but since we are a public university, we do not assume that students have their own computer.

\section{Summary and Conclusions}

Cal Poly has taken advantage of its position as a member of the SYNTHESIS Engineering Education Coalition to implement a local version of the capability of the NEEDS infrastructure on its campus. This version has used existing university resources found on most campuses with engineering programs: the library, UNIXbased local area networks, and information services. It has been observed by the principals that these resources are very reasonably priced, and therefore, are accessible by other 
universities with engineering programs. Hence, there is a natural mechanism to emulate the NEEDS concept on each engineering campus, thus making digital curricular material easily available for both students and faculty now. Local development of the NEEDS infrastructure will not only facilitate the development and use of digital courseware materials, but pave the way for the expected availability of the national infrastructure that NEEDS will provide for all programs to access and share curricular material.

One of the major ancillary advantages that this local development has brought to the campus has been the opportunities for more collaboration among the various communities that compose the university of today. It is expected that this collaboration will expand via NEEDS to all engineering programs for the development of new and exciting curricular materials.

Those that would like more information on the local capability at Cal Poly so that they can replicate those capabilities on their campus are encouraged to contact the authors. It is recognized that the technology is changing rapidly, and fortunately, with improved cost and performance; therefore any specific recommendation will quickly be obsolete. Nevertheless, we encourage all to get involved as soon as possible because our experience is that this technology supports improved student learning.

\begin{tabular}{|c|c|}
\hline \multicolumn{2}{|r|}{ 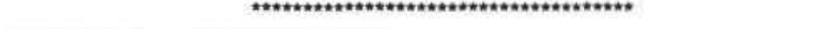 } \\
\hline LOCATION: & Stacks $2 d-5$ th $f l$ \\
\hline CALL NO: & TK871.96.B55 W66 1991 \\
\hline AUTHOR: & Woody, Steve \\
\hline TITLE: & The bipolar junction transistor \\
\hline PUBLISHER: & $\begin{array}{l}\text { Version 1.0-San Luis Obispo, Calif. : California } \\
\text { Polytechnic State University, Electronic \& Electrical } \\
\text { Engineering Dept., Technology Assisted Instruction } \\
\text { Laboratory } 1991\end{array}$ \\
\hline
\end{tabular}

LOCAL NOTE: System requirements: IBM PC/XT/AT/PS/2 or compatible; high density 3.5 or 5.24 disk frive or hard disk; EGA graphics monitor; telecommunitcations software; Internet access. Mode of access: Ftp to gauss.elee.calpoly.edu. anonymous login. At host prompts enter commands: cd tai; binary; prompt; mget bjtran exe; quit. Download self-extracting bjtran.exe from your local account to a separate DOS directory as a binary file. Execute file bjtran.exe to unzip module files. To begin, enter "bjt".

NOTE 1: SUMMARY: Fundamentals, terminal characteristics, Ebersmoll equations, parametric curves, and regions of operation for bipolar junction transistors

CONTENTS: 1 . Fundamentals - 2. Two-port representation 3. Terminal characteristics - 4 . Regions of operation -5. Interactive tutorial - 6 . Exit.

NOTE 2: Title from title screen; title on menu screen: The commonemitter bipolar junction transisitor.

"February, 1991"

"With support from the National Science Foundation"

SUBJECT 1: Bipolar transistors--Computer-assisted instruction. SUBJECT 2: Junction transistors--Computer-assisted instruction.

ADD AUTH 1: California Polytechnic State University, San Luis Obispo. Electronic and Electrical Engineering Dept. Technology Assisted Instruction Laboratory

ADD TITL 1: Fundamentals of electrical engineering.

ADD TITL 2: Common-emitter bipolar junction transistor.

QUALIFIER: Software, 1991

Figure 1 MARC Record Example 
Anonymous FTP guide (thanks to Mike Belshe):

These instructions specifies how to make a DOS application available via anonymous ftp on gauss.elee.calpoly.edu, and also how to extract the files to your DOS machine.

\subsection{Placing files in the Anonymous ftp directory}

1. Compress the DOS files into a single self extracting archive using ZIP. There are two reasons for doing this. For one, it saves disk space and also saves time downloading since the size of the download is smaller. Secondly, by having the files self-extracting, the user does not need to be familiar with ZIP in order to uncompress the files.

To create a self-extracing archive, do the following: ZIP -A MYFILE.ZIP FILE1 FILE2 FILE3

This will create a zip file called "MYFILE.ZIP" which will contain FILE1, FILE2 and FILE3.

To make the zip file a self extracting archive, type MAKESFX MYFILE.ZIP

2. Upload the files to gauss.elee.caipoly.edu

3. Move the files to the ftp directory.

To copy the files to the ftp directory, do the following: cp MYFILE. EXE /usr/ftp/pub/tai chmod 644 /usr/ftp/pub/tai

That's it! Your files are now available via anonymous ftp.

2.0 Downloading the files from anonymous FTP

1. Login to your UNIX account.

2. Use ftp to access gauss.elee.calpoly.edu

Type the following at your UNIX prompt: ftp gauss.elee.calpoly.edu

When you get a prompt back, type "anonymous" as your login.

Then type your name as your password.

3. You are now logged into gauss. Get the files

Type the following at the ftp> prompt:

cd pub/tai

binary

get MYFILE.EXE

quit

4. Now download the files from UNIX to your PC.

I recommend using zmodem ("sz MYFILE.EXE" is the UNIX command)

5. On your DOS machine, decompress the files.

Type the following: MYFILE.EXE

The application will now self-extract and be ready for use! 